\title{
Makan@Local Chatok: Mobile Eatery Recommendation System Based on Local Knowledge
}

\author{
https://doi.org/10.3991/ijim.v14i05.13357 \\ Siti Mahfuzah Sarif $\left.{ }^{(}\right)$, Zurina Hanafi, Shafinah Farvin Packeer Mohamed, \\ Syamsul Bahrin Zaibon, Mohamad Farhan Mohamad Mohsin \\ Universiti Utara Malaysia, Kedah, Malaysia \\ ctmahfuzaheuum. edu.my
}

\begin{abstract}
This paper discusses a unique business model of eatery recommender system based on local knowledge using mobile platform. The business model is developed to define the business concept of the innovation which is a rural innovation involving multiple entities (locals, eatery owners and users who are searching for eatery). The innovation highlights on local knowledge crowdsourced from the participation of locals through gamification activities included in the mobile app. In achieving the aim, the design science methodology was adapted in this study which consists of 4 phases: (i) Awareness of Problem, (ii) Suggestion, (iii) Evaluation, and (iv) Conclusion. The proposed business model was developed through a few activities including literature review, comparative study dan preliminary study. Then, the study continued with developing a prototype known as Makan@Local Chatok (M@LC) app and evaluated the app in terms of its usability aspects. Results from the usability testing concludes that the app is perceived as easy to use. It was also found that the proposed business model has been well-accepted by users. In conclusion, it is hoped that this study will not only demonstrate the potential and impact of mobile eatery recommendation system using local knowledge, but also provide a capstone on business research in the field of tourism industry.
\end{abstract}

Keywords-Mobile recommender system, local knowledge, gamification

\section{Introduction}

Recommendation systems have evolved in parallel with the technology. They were initially developed based on demographic, content-based and collaborative filtering. With the recent marriage of smart gadgets and the Internet, there is a growing trend towards the use of information from the Internet. Recommendation systems are particular type of personalized system, which filters information and presents only what is relevant to an individual. According to Lathia (2015), mobile location-based recommendation systems are accessed via mobile devices, use location data (current or otherwise, e.g. historical), involves and leverages users' movement around a physical space and, most importantly, provide personalised recommendations that are tailored to users' preferences. Commonly, mobile location-based recommendation systems are 
used extensively in venue recommendation although there are location-based social matching applications, tailored to find people of interest in particular locations, and behaviour-oriented applications, such as those related to sport and physical activity. As far as venue recommendation is concerned, White and Buscher (2012) highlight the impacts of personalizing results based on local knowledge and how to leverage that knowledge to benefit non-locals. Yet, to the best of our knowledge, there is surprisingly little research on incorporating local knowledge in the design of mobile location-based recommendation systems.

However, there are a significant number of mobile recommenders available for smart phones targeting eatery venue recommendation. The majority of applications are designed to help locate either nearby food outlet (for example Hungry MY, Urbanspoon, Where to Eat?, Upocket, Eat Drink KL, etc.), nearby branded food outlet (for example Starbucks, Nandos, McDonalds, Dominos), or nearby halal food outlet (for example Halal Food Finder, Zabihah, Zomato, hungryhouse, Halalspot, etc.). More often, the recommendations that users get are not satisfactory due to many factors (Bozhi et al., 2014). One of the factors is the lack of systematic approach to model the design of such a system. Moreover, most of these existing mobile recommendation systems fail to exploit information, evaluations or ratings provided through local knowledge.

Local knowledge refers to the cumulative and complex bodies of knowledge, knowhow, practices and representations that are maintained and developed by peoples with extended histories of interactions with the natural environment. It is part of a complex ecosystem that includes language, attachment to place, spirituality and worldview. Study of local knowledge has benefited in many different areas such as disaster management (Peters-Guarin et al., 2012), wildlife conservation (Sousa et al., 2014; Padmanaba et al., 2013), contagious disease prevention (Dickin, Schuster-Wallace, \& Elliott, 2013), and ecological management (Mellado et al., 2013). In addition, there are also growing numbers of studies that incorporate local knowledge in the design of decision support system such as Yin et al. (2013); Oliver et al. (2012); Yanagisawa and Yamamoto (2012); Nakahara, Yanagisawa and Yamamoto (2012); and Bao, Zheng and Mokbel (2012). However, the studies focused more on the integration of several recommendation system methods and improvising the algorithms or it's application at managerial level but least on modeling the local knowledge for social recommendation.

This suggests that an empirical work is required to depict the business model which can be used as a guideline to develop mobile recommendation system using local knowledge. This business model is important to improve application and development of such a system as well as the quality of the recommendation, which not only can assist in decision-making, but also elevate the user experience by providing trust aware information through the modeling of local knowledge. Consequently, the study has proposed a business model which accentuates local knowledge in the development of mobile recommendation system for eatery.

The remaining of this paper is organized as follows: Section 2 provides the literature review and Section 3 discusses the methodology. The result is presented in Section 4, followed with the discussion and conclusion in Section 5. 


\section{$2 \quad$ Literature Review}

A number of related scholarly sources have been reviewed to identify trends, gaps and debates in this research, namely under the topic of living lab, mobile recommendation system, mobile app gamification, local knowledge and related case studies.

\subsection{Living lab (Rural innovation)}

There is a growing trend to involve citizens in urban and rural development to make these areas more suitable to their needs and prevent social problems. For example, city centres and neighbourhoods have increasingly been serving as regional living labs, which are ideal platforms to explore the needs of users as residents and citizens. A living lab is a research concept and often a user-centred, open-innovation ecosystem. It operates in a territorial context (e.g. city, agglomeration, region), integrating concurrent research and innovation (public-private-community partnership). The concept is based on a systematic user co-creation approach integrating research and innovation processes. These are integrated through the co-creation, exploration, experimentation and evaluation of innovative ideas, scenarios, concepts and related technological artefacts in real life use cases. Such use cases involve user communities, not only as observed subjects but also as a source of creation. This approach allows all involved stakeholders to concurrently consider both the global performance of a product or service and its potential adoption by users. This consideration may be made at the earlier stage of research and development and through all elements of the product lifecycle, from design up to recycling.

At least three types of living labs can be distinguished.

First, community and social space areas can serve as technology-assisted research environments, in which users give feedback on products and services through web pages, mobile applications or sensor-based methods (Bergvall-Kareborn et al., 2009). In this context, the goal of a living lab is to improve a living environment or local services, such as housing or public transformation.

Second, users can co-create social related artefacts and local services, such as communal yards, or educational services (Pallot et al., 2010).

Third, a living lab can develop new kinds of social planning using new tools and processes with the engagement of citizens (Edwards-Schachter et al., 2012). In this case, the goal is to facilitate the vision-making of the area and planning procedures, and increase the access and mutual learning of stakeholders. Thus, a living lab can provide a platform for stakeholders to participate in a city's planning initiatives and decision making. In new urban areas, the boundaries between different living labs may become blurred because the many diverse actors may be simultaneously collaborating in multiple labs. 


\subsection{Mobile recommendation system}

Recommender systems have been extensively utilized as a means of reducing the information overload and offering travel recommendations (e.g. place to eat) to users. Recommender systems can be defined as programs which attempt to recommend the most suitable items (products or services) to particular users (individuals or businesses) by predicting a user's interest in an item based on related information about the items, the users and the interactions between items and users (Bobadilla, Hernando, \& Gutierrez, 2013).

Mobile phones are becoming a primary platform for information access and when coupled with recommender systems technologies they can become key. In the literature, the mobile recommender systems in tourism-related area (including eatery recommendation) can be classified as follows:

- Web-based systems: They are typical client-server system, where a mobile application corresponds to the presentation tier and the recommendation logic is maintained on the server. They exploit sufficient computational resources of the recommendation system's server to execute sophisticated based recommendation system servers that may be based on mobile browsers or implemented as Java ME, Android or iOS applications which offer basic offline functionality, persistent storage and rich user interface.

- Standalone systems: These refer to full-fledged mobile applications that incorporate the recommendation logic and the tourist content. They are typically downloaded and installed on mobile devices thereafter functioning in disconnected mode. As a result, recommendation techniques based on matching different user profiles are out of scope in these systems.

- Web-to-mobile systems: These systems provide a typical web interface for the previsit stage whereby users initially select content and then build a customized tourist application, incorporating the recommendation logic. Similar to standalone systems, they are subsequently downloaded and installed on a mobile device thereafter executing offline. On-demand connection to a remote server may be used to update POI information or public transportation data.

\subsection{Multi criteria decision making}

Multicriteria Decision Making (MCDM) technique is defined as "making preference decision over the available alternatives that are characterized by multiple, usually conflicting attributes" (Triantaphylluo, 2000). Among the MCDM techniques commonly being used for evaluation are the Weighted Sum Method (WSM), Technique for Order Preference by Similarity to Ideal Solution (TOPSIS), outranking methods, fuzzy multiple criteria and Analytic Hierarchy Process (AHP). In this study, the most appropriate MCDM technique is WSM or also known as Simple Additive Weighting. In WSM, the score is calculated by multiplying the comparable rating of each eateries criteria with the weight values assigned to the attributes and summing these values over all attributes. This technique is utilized widely for calculating the final grade values in the multiple criteria problems (Kontos, Komilis, \& Halvadakis, 2005). The total score 
for each alternative then can be computed by multiplying the comparable rating for each attribute by the importance weight assigned to the attribute and then summing these products over all the attributes.

Referring to Jadav and Sonar (2018), WSM is easy to be used. Moreover, it is a proportional linear transformation of the raw data which means that the relative order of magnitude of the standardized scores remains equal (Afshari, Mojahed, \& Mohd Yusuff, 2010). Besides, it has been used by previous studies in selection, for instance Omar, Trigunarsyah and Wong (2018) utilized WSM to select consultant. Other than that, WSM was used in a decision support system to evaluate procurement of goods based on particular criteria (Nugraha, 2013), select the best school in Palembang (Putra, Abdillah, \& Yudiastuti, 2016) and to determine employee's increment rate (Sahir, Rosmawati, \& Minan, 2017). For this study, the weight values are gathered from the survey, which was rated by the respondents. Then, the best eatery is recommended based on the score obtained.

\subsection{Mobile app gamification}

Gamification is a powerful new strategy to influence and motivate groups of people (Law, Kasirun \& Gan, 2011). It applies game mechanics to non-game activities to change the user's behavior of an application. It improves the engagement of user by keeping score of points earned through various activities on the application (Law, Kasirun \& Gan, 2011). For instance, like the recent gamified mobile apps or a related service such as Waze, a GPS navigation app that provides turn-by-turn navigation information and user-submitted travel times and route details, while downloading location-dependent information over a mobile telephone network. Waze rewards users with points that allow them to advance through five levels. It also offers achievements and shows them their overall rank on the platform. Gamification is utilised as a mean to build up user loyalty, and not so much to gain their long-term engagement.

Several components when creating a gamification system have been highlighted in the literature (Kapp, 2012; Erenli, 2012; Dicheva et al., 2015):

- Goals: Goals are an essential component of fun. They give a sense of purpose to the system and make users feel pleased when succeed and empower them with a feeling of accomplishment when they achieve them.

- Rules: Rules are repetitive and continuous actions users need to do and they are tightly integrated with the main offering of the product. The best type of rules are simple to understand and to execute and require minimal or no input from users.

- Feedback: Give feedback to users, specifically progress feedback. Users need to see feedback, specifically progress feedback, and to see how well they are doing in the context of the goals we set for them and the rules that they've agreed upon. It comes in different visual forms like progress bars, levels, encouragement messages, animations etc.

- Rewards: A common rewards setup includes a points system that quantifies the performance or the users, badges that are awarded for special achievements, and leaderboards that rank users based on the previous two. This mix is commonly 
referred to as "BPL" (Badges, Points and Leaderboards) and is often wrongly understood as the definition of gamification itself.

- Motivation: Offer motivation for users to act. There are two types: intrinsic motivation, that comes from within us like curiosity, pride or a sense of achievement and extrinsic motivation that comes from outside us like money, grades or praises.

\subsection{Local knowledge}

Local knowledge refers to the cumulative and complex bodies of knowledge, knowhow, practices and representations that are maintained and developed by peoples with extended histories of interactions with the natural environment. These cognitive systems are part of a complex that also includes language, attachment to place, spirituality and worldview. Study of local knowledge has benefited in many different areas such as disaster management (Peters-Guarin, McCall, \& van Westen, 2012), wildlife conservation (Sousa et al., 2014; Padmanaba et al., 2013), contagious disease prevention (Dickin, Schuster-Wallace, \& Elliott, 2013), and ecological management (Mellado et al. 2013). In addition, there are also growing numbers of studies that incorporate local knowledge in the design of decision support system such as Yin et al. (2013); Oliver et al. (2012); Yanagisawa and Yamamoto (2012); Nakahara, Yanagisawa and Yamamoto (2012); and Bao, Yu, and Mokbel (2012). However, its either the studies were focusing more on the integration of several recommendation systems methods and improvising the algorithms or it's application at managerial level but least on modeling the local knowledge for social recommendation.

\subsection{Local knowledge in existing apps (Case studies)}

The main objective of this study is to design and develop mobile recommendation app which incorporate local knowledge as its focal point. Hence, seven related apps have been identified and examined, which provide basis for future design and development works.

The information from the seven case studies is broken down into three main categories (i.e., platform/mode, features, and local knowledge format) and then summarized as displayed in Table 1. Mobile apps have both format and content. Format refers to the form or structure of the information. Content refers to the meaning of the information. Both format and content are quantified and summarized as displayed in Table 1. 
Table 1. Comparative analysis of seven existing mobile apps for eatery recommendation based on local knowledge

\begin{tabular}{|c|c|c|c|c|}
\hline No. & $\begin{array}{l}\text { Apps } \\
\text { Name }\end{array}$ & $\begin{array}{l}\text { Platform/ } \\
\text { Mode }\end{array}$ & Features & Local Knowledge Format \\
\hline 1 & $\begin{array}{l}\text { Like a } \\
\text { Local }\end{array}$ & $\begin{array}{l}\text { Website, } \\
\text { Mobile app } \\
\text { (offline) }\end{array}$ & $\begin{array}{l}\text { Recommend venue of } \\
\text { eateries \& sights with } \\
\text { addition of tips \& tour } \\
\text { activities } \\
\text { works like e-travel } \\
\text { guide/book }\end{array}$ & $\begin{array}{l}\text { Tips \& tour with locals } \\
\text { (host/guide/show talent) } \\
\text { Register as local/earn points \& } \\
\text { rewards }\end{array}$ \\
\hline 2 & $\begin{array}{l}\text { Ask a } \\
\text { Local }\end{array}$ & $\begin{array}{l}\text { Website, } \\
\text { Mobile app }\end{array}$ & $\begin{array}{l}\text { Support multi-language } \\
\text { queries } \\
\text { recommend venues and } \\
\text { activities } \\
\text { location-based } \\
\text { recommendation system }\end{array}$ & $\begin{array}{l}\text { Embedded in the form of storytelling } \\
\text { post (i.e., collection of best } \\
\text { blogs/websites that shares } \\
\text { story/info/updates about a place } \\
\text { including eatery) }\end{array}$ \\
\hline 3 & $\begin{array}{l}\text { Spot } \\
\text { Luck }\end{array}$ & Mobile app & $\begin{array}{l}\text { Location-based } \\
\text { recommendation system } \\
\text { Uses artificial intelligence } \\
\text { based on parameters like } \\
\text { weather, time and day to } \\
\text { determine the } \\
\text { recommendation and other } \\
\text { deals. }\end{array}$ & $\begin{array}{l}\text { Involve participation of local } \\
\text { businesses (provide discounts) } \\
\text { Include local info (e.g. weather) }\end{array}$ \\
\hline 4 & Localeur & $\begin{array}{l}\text { Website, } \\
\text { Mobile app } \\
\text { (offline/ } \\
\text { online) }\end{array}$ & $\begin{array}{l}\text { Nearby recommendation } \\
\text { system that uses } \\
\text { collaborative filtering from } \\
\text { verified locals }\end{array}$ & $\begin{array}{l}\text { Verification of locals is made through } \\
\text { social media account. }\end{array}$ \\
\hline 5 & $\begin{array}{l}\text { Like a } \\
\text { Hipster }\end{array}$ & Mobile app & $\begin{array}{l}\text { Nearby recommendation } \\
\text { system } \\
\text { Uses data from Foursquare, } \\
\text { Facebook, Yelp \& Google } \\
\text { Map }\end{array}$ & $\begin{array}{l}\text { Suggests nearby eateries, activities, } \\
\text { and places with local pop-culture } \\
\text { influences (i.e., hipster) }\end{array}$ \\
\hline 6 & $\begin{array}{l}\text { Spotted } \\
\text { by } \\
\text { Locals }\end{array}$ & $\begin{array}{l}\text { Mobile app } \\
\text { (offline) }\end{array}$ & $\begin{array}{l}\text { Can work } 100 \% \text { offline for } \\
\text { maps and tips } \\
\text { Nearby recommendation }\end{array}$ & $\begin{array}{l}\text { Works like a tour/travel guide with } \\
\text { insider tips from locals through } \\
\text { specific crowdsourcing concept }\end{array}$ \\
\hline 7 & $\begin{array}{l}\text { With } \\
\text { locals }\end{array}$ & Website & $\begin{array}{l}\text { Register } \\
\text { find \& book experience } \\
\text { with local host } \\
\text { do payment online }\end{array}$ & $\begin{array}{l}\text { Locals offer experiences \& skills to } \\
\text { travelers (e.g., things to do \& food } \\
\text { experience) } \\
\text { authentic review system (only verified } \\
\text { locals) } \\
\text { verified supplier system - based on } \\
\text { personal contact }\end{array}$ \\
\hline
\end{tabular}




\section{$3 \quad$ Methodology}

This study adapted the design science research methodology as the generally accepted methodology in information system that supports a pragmatic research paradigm that calls for the creation of innovative artifacts to solve real-world problems (Simon, 1996). In this research, the methodology from Vaishnavi and Kuechler (2007) is adapted to achieve the study objectives. There are 4 phases involved:

i) Awareness of Problem

ii) Suggestion

iii) Evaluation

iv) Conclusion

\subsection{Awareness of problem phase}

The problem statement of this study is extracted from the literature review and comparative study on the use of local knowledge in designing mobile location-based recommender system.

Seven samples of related mobile apps have been examined and analysed to provide sufficient information on common features for such apps and also how local knowledge is being embedded in the apps (Sarif, 2018). The study has learned about the review system (i.e., how the app verify each review from locals), the information format (i.e., either its from the collection of personal stories, blogs, or websites), back end of the recommendation system (i.e., contextual-aware, locational-aware, collaborative filtering) and the additional feature related to local participation in the system (i.e., reward system, points collectible system, etc.).

Apart from that, a preliminary study (survey) was also conducted on exploring the relevant aspects for eatery recommendation criteria. 429 respondents were participated in the preliminary study and they have shortlisted 8 criteria to choose for eatery places and some of the best places to eat in the chosen area (Changlun and Sintok).

These data were gathered as a first phase of data collection. All these steps are important to build the awareness of the research problem.

\subsection{Suggestion phase}

The phase involves design and development task where requirements of the system are considered in developing the M@LC apps. This phase consists of three activities; construct a M@LC Business Canvas Model, develop a M@LC User Stories, and develop the $\mathrm{M} @ \mathrm{LC}$ prototype.

\subsection{Evaluation phase}

This study evaluated the usability aspects of the prototype (Makan@Local Chatok app). It involved survey (questionnaire), and interview to measure the usability of the system. The survey has 10 items which tested the usability aspects of the prototype such 
as perception, ease of use, willing to use frequently, and confident to use (Nielsen, 1994). 42 respondents participated in the survey which were selected based on purposive sampling who have been to the eatery places in the selected area (Sintok and Changlun).

In addition, an interview session to business owner was also conducted to get the opinion from them. The data was useful to get the qualitative feedback about the prototype.

\subsection{Conclusion phase}

The final phase is a conclusion where the results of survey and review were analysed and explained. The design iteration process of the prototype was performed to visualize the final form of the model in accordance to users' feedback. Once the last iteration is done, the proposed model is finalized, then the direction and future research to promote improvement on this research are elaborated as part of the conclusion phase.

\section{$4 \quad$ Result and Finding}

The result and finding is divided into three sections. Initially, preliminary survey has been conducted in order to obtain eateries and criteria for evaluating these eateries. After that, the prototype of the app is developed. In order to verify the app, usability test was carried out for business owner and app users.

\subsection{Preliminary survey}

A preliminary survey has been done in the beginning part of the study order to obtain information to be included in the system. There are 429 respondents that has been accepted from this survey. $42.7 \%$ of the respondents are male while the rest $53.7 \%$ are female. Most of the respondents' are young adults, with age between 20 and 30 years old, accounted to almost 200 respondents. Less than 150 respondents aged between 30 to 40 years old while the rest are below 20 or more than 40 years old. Since most of the respondents are young adults, almost 350 of respondents earning below RM3000 per month. The next part of the questionnaire is about the origin of the respondents. This is important because this study is focusing on local knowledge. Therefore the locality of respondents ensures that the information obtained is fed by local people who have local knowledge about restaurants and local eateries in Changlun and Sintok.

The survey has been conducted around Changlun and Sintok and $85.2 \%$ of the respondents are local. The locality of the respondents is the main concern since their inputs are important information that has been used in app development. 17 local eateries have been selected by the respondents together with their preferred menus. Based on the suggested menus, eateries are divided according to meal time namely breakfast, lunch and dinner. This meal time is later used as the first step in selecting eateries in the app. Criteria of eateries or restaurant selection are chosen based on literature review. Kim and Chung (2011) list restaurant selection criteria that have been 
adapted in this study. Food reviews criteria in various food finder apps are also considered. Eight criteria has been selected in evaluating the eateries namely food quality, food taste, price, customer service, eateries' environment, facilities provided, eateries cleanliness and variety of menu.

\subsection{M@LC business canvas model}

The M@LC business model canvas is proposed as depicted in Figure 5 below. The business model is developed to define the business concept of M@LC app which is a rural innovation involving multiple entities (locals, eatery owners and users who are searching for eatery). The innovation highlights on local knowledge crowdsourced from local participation using the M@LC app. As for the revenue stream, the innovation generates revenue from the subscription fees from participated eatery owner and also ad sales.

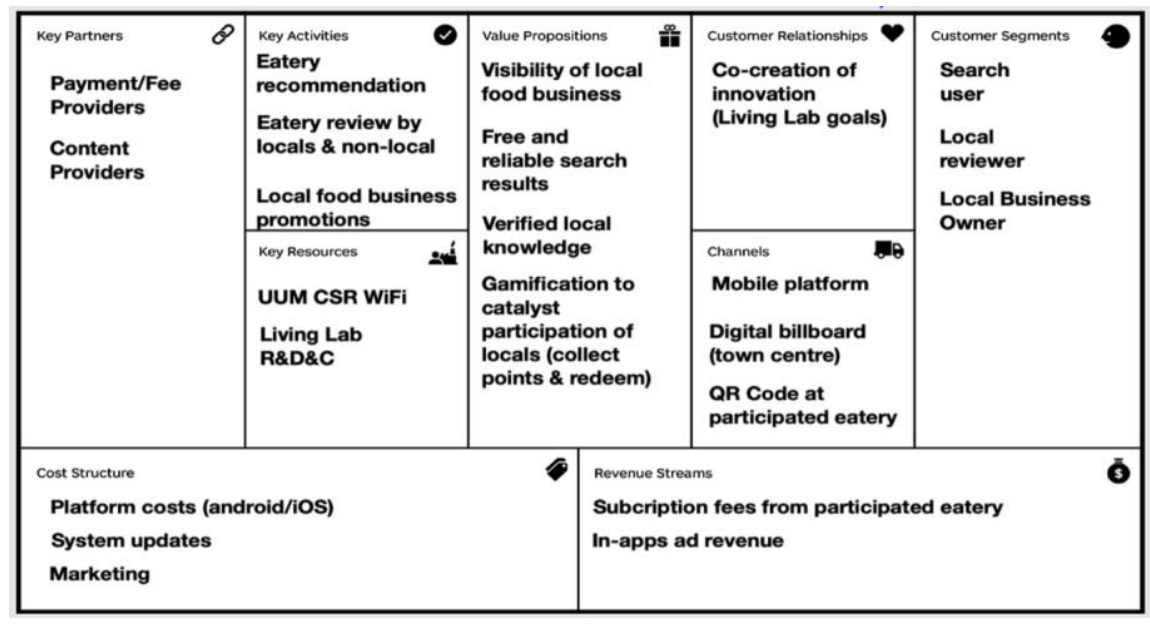

Fig. 1. M@LC Business Model Canvas

\subsection{M@LC user stories}

User stories are an increasingly popular textual notation to capture requirements in agile software development. This study employ user stories to capture requirements for the development of Makan @Local Chatok app as displayed in Table 2. 
Table 2. User stories of Makan @Local Chatok

\begin{tabular}{|c|c|c|}
\hline & System Functionality & User Stories \\
\hline 1 & Eatery recommendation & $\begin{array}{l}\text { Eatery recommendation } \\
\text { 1. As a <user>, i can search for eatery by setting the meal time that } \mathrm{i} \\
\text { prefer } \\
\text { 2. As a <user>, i can choose from the top } 5 \text { local chatok (eatery) } \\
\text { recommended by the locals as presented in the result page } \\
\text { 3. As a <user>, i can view the details about the selected local chatok } \\
\text { 4. As a <user>, i can get the direction to the selected local chatok }\end{array}$ \\
\hline 2 & Food reviews & $\begin{array}{l}\text { Food reviews } \\
\text { 1. As a <reviewer>, i can scan the QRcode at the participated local } \\
\text { chatok. } \\
\text { 2. As a <reviewer>, i must create account before i can review. } \\
\text { 3. As a <reviewer>, i can manage my account. } \\
\text { 4. As a <reviewer>, i must verify that I am local. } \\
\text { 5. As a <reviewer>, i can give review about the quality of the menu } \\
\text { at the selected local chatok. } \\
\text { 6. As a <user>, i must sign-up/sign-in into the apps to give review. } \\
\text { 7. As a <user> i can give review about the quality of the menu at the } \\
\text { visited local chatok. } \\
\text { 8. As an <admin> i can check the reviews to ensure that only the } \\
\text { reviews written by the locals are used for providing eatery } \\
\text { recommendations in the apps. } \\
\text { 9. As an <admin>, i can delete inappropriate reviews written by the } \\
\text { reviewers. } \\
\text { 10. As a <reviewer/user/business owner> i can view reviews written } \\
\text { by other reviewers. } \\
\text { 11. As a <reviewer/user/business owner>, i can give comments/get } \\
\text { feedbacks to/from the reviews that i view. }\end{array}$ \\
\hline 3 & $\begin{array}{l}\text { Points collection/ } \\
\text { redemption }\end{array}$ & $\begin{array}{l}\text { Points collection/redemption } \\
\text { 1. As a <user>, I can collect points after leaving reviews at the } \\
\text { restaurants that I visited. } \\
\text { 2. As a <user>, I can redeem points subject to benefits offered by } \\
\text { business owners. } \\
\text { 3. As an <admin>, I can check points collected by all users. } \\
\text { 4. As an <admin>, I should ensure that the points redeemed by the } \\
\text { users for the benefits will be deducted accordingly. } \\
\text { 5. As a <business owner>, I am able to view the reviews about my } \\
\text { restaurant. } \\
\text { 6. As a <business owner>, I will update offers/benefits for points } \\
\text { redemption by user. } \\
\text { 7. As a <business owner>, I will allow for points redemption at my } \\
\text { restaurant. }\end{array}$ \\
\hline 4 & Business marketing & $\begin{array}{l}\text { Business Marketing } \\
\text { 1. As a <business owner>, i can sign up to this service and } \\
\text { advertise my outlet } \\
\text { 2. As a <business owner>, i want to describe myself on my own } \\
\text { profile page in a semi-structured way so that potential customers } \\
\text { can learn about our outlet. That is, I can fill in predefined fields, } \\
\text { but also have room for a free-text field or two. } \\
\text { 3. As a <business owner>, i want my profile page to include } \\
\text { additional details about my outlet so that potential customers can } \\
\text { learn about us and decide if we offer something for them. }\end{array}$ \\
\hline
\end{tabular}




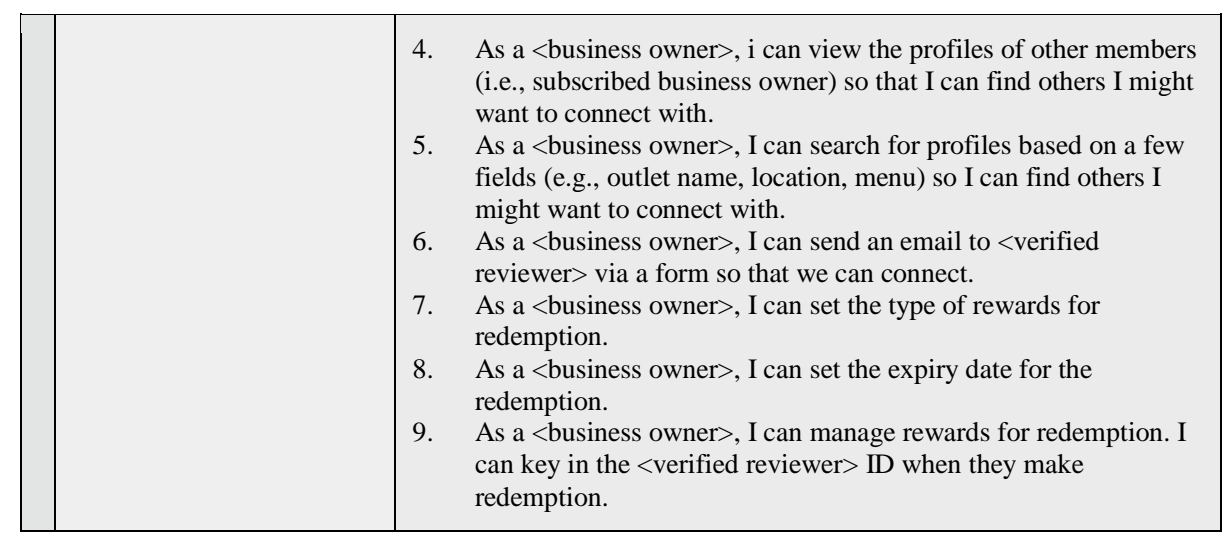

\subsection{M@LC prototype}

The Makan@Local Chatok app is a native app, however it is connected to the webbased application through a shared database. The type of users for the app consists of admin, reviewer, user, and eatery owner. The normal flow of the app starts with user searching for eatery through choosing meal time, and a list of top five eateries will be listed as options. User then get to have a closer view of the eatery info or rate the eatery after experiencing the food at the chosen eatery. The previous descriptions are illustrated in the following Figures 2.

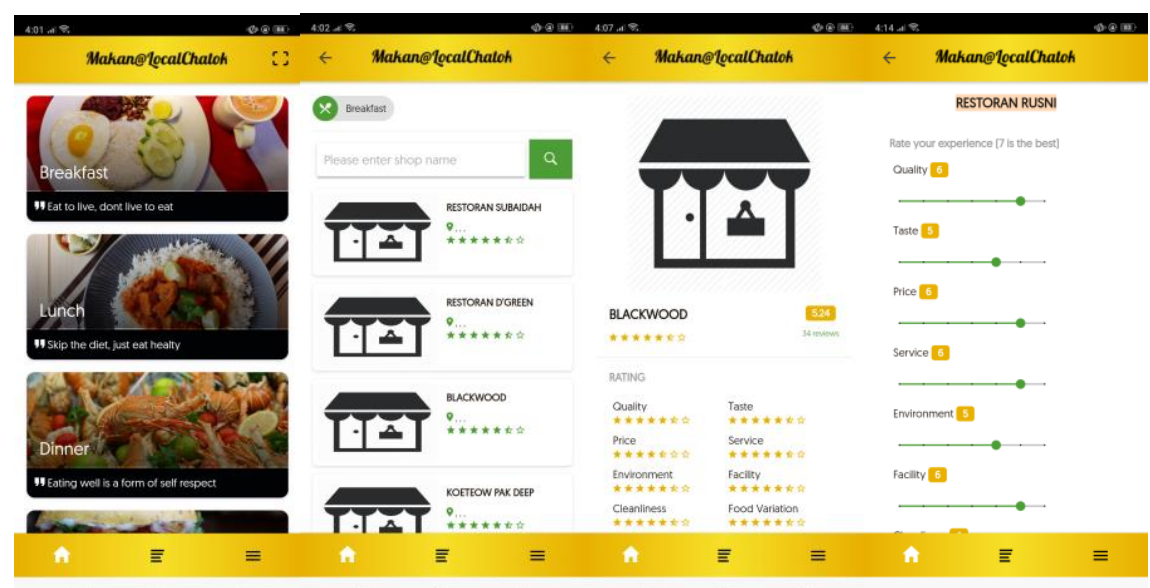

Fig. 2. Screenshots of steps in using M@LC app

In addition to rating the eatery, users may also give their textual reviews about the eatery. This is one of the ways the app crowdsourced the local knowledge from the locals. Once the user completed the rating and review process, they will be rewarded with points that can be redeemed at the particated eatery. This is part of the gamification 
feature in the app to engage the locals participation with the system and motivate them. The previous descriptions are illustrated in the following Figure 2.

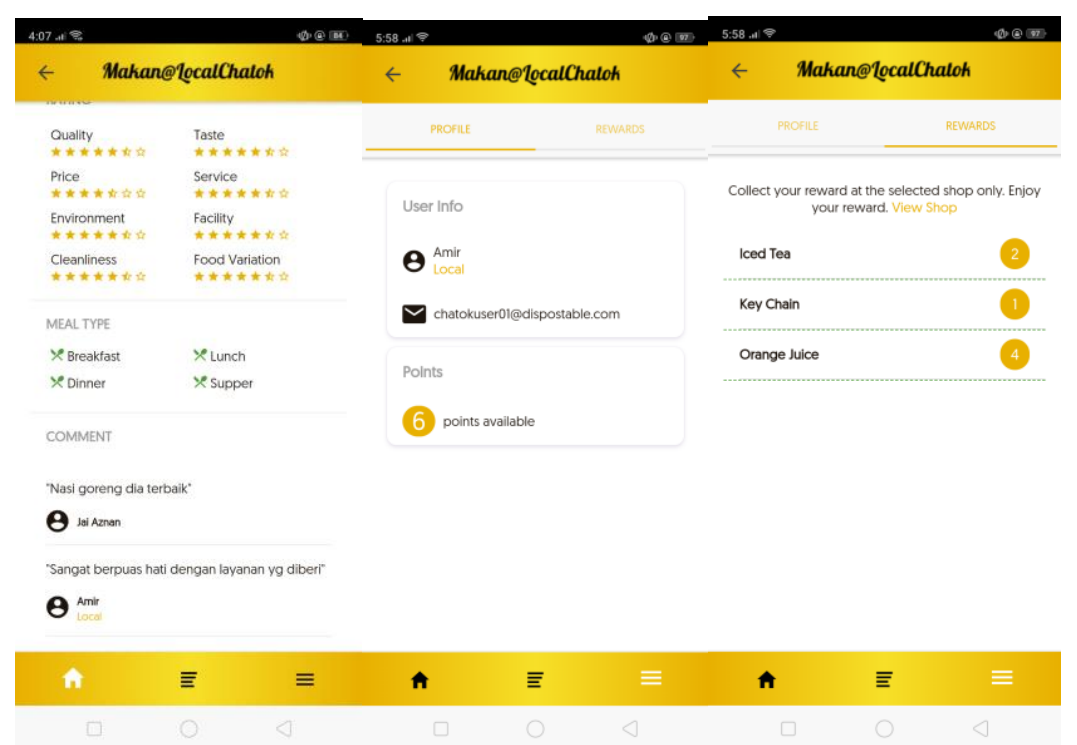

Fig. 3. Screenshots of gamification features in M@LC app

Another set of interface is set up for business owner through the localchatok.com website. The website enables the business owner to manage their account once they are signed up for this service. The website consists of a number of important functions, namely setting up information for the eatery, updating menu, setting up rewards/point, managing redemptions and approving reviews. Figure 4 illustrates part of the functions mentioned earlier. 

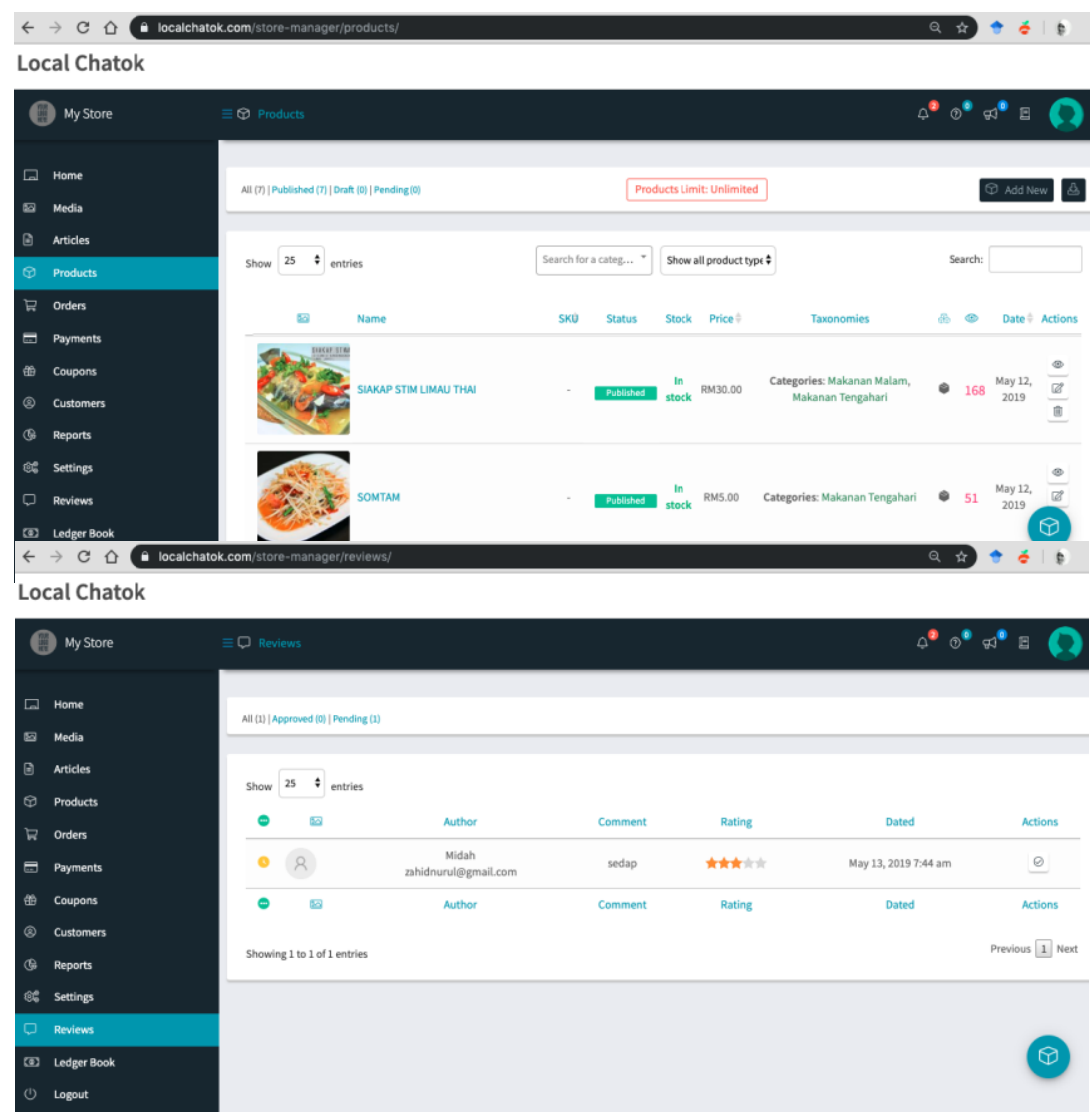

Fig. 4. Screenshots of localchatok.com website

M@LC app has been tested to potential users who are living in Changlun and Sintok. This has been done to business owners and app users. For business owners, the app and the system were presented. In the end, if they are interested to be part of business owners in the app, a Letter of Intent (LOI) was signed to show their interest. A sample of LOI is attached in Appendix B.

The information gathered from app users is crucial in order to get feedback for the app enhancement and modification. The demographic of the respondents is shown in Figure 5. 


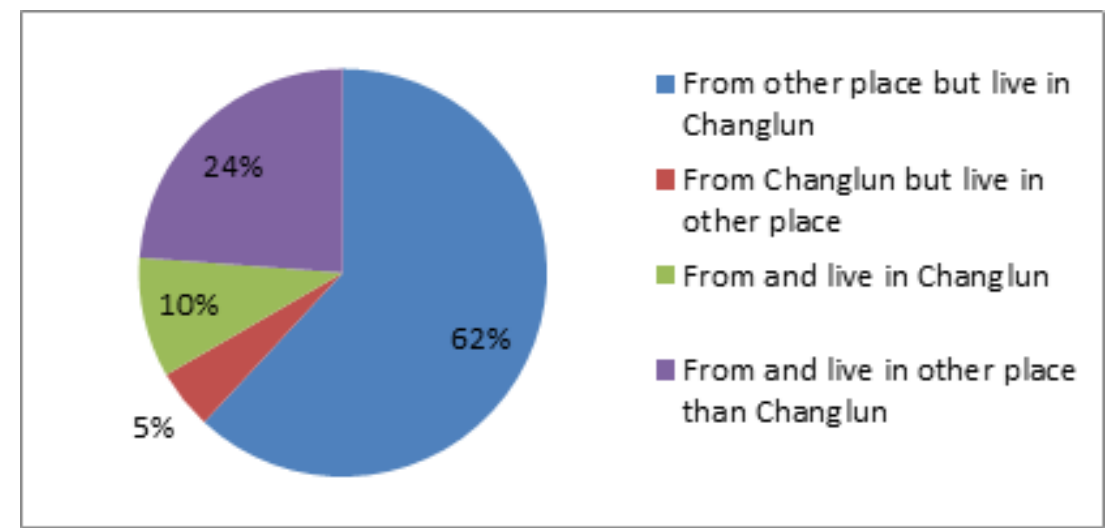

Fig. 5. Demographics of Respondents

Figure 15 shows that $76 \%$ of the respondents are local people who have local knowledge about Changlun and Sintok, whether they come from or live in this area. The rest $24 \%$ are considered as non-local. Perception is an important measure in the usability testing. It shows how the users think about the app. The perception of M@LC app is shown in Figure 6.

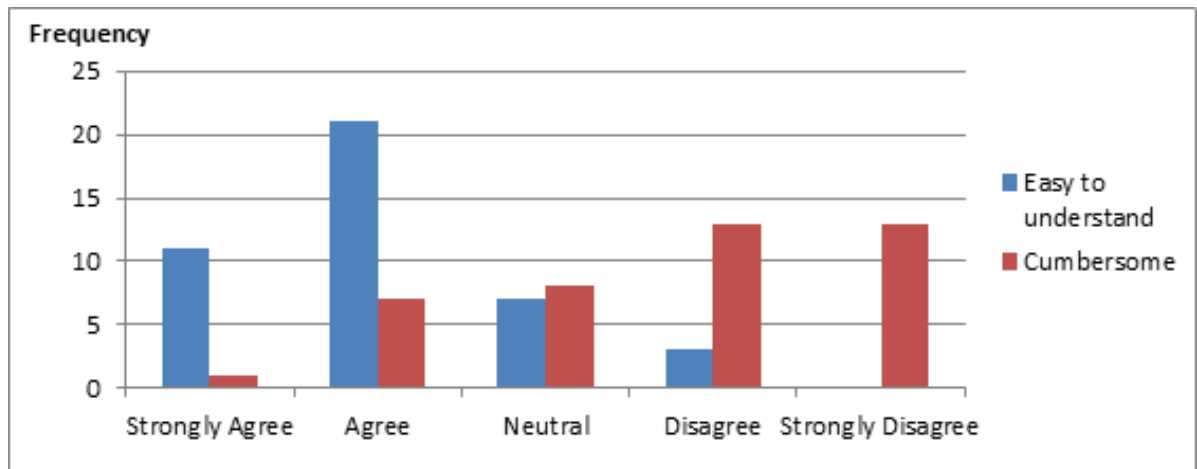

Fig. 6. Perception of M@LC App

From Figure 16, most of the respondents found that M@LC app is easy to understand with more than half respond to strongly agree. However, about three respondents found that the app is cumbersome. Ease of use is another measure taken in usability testing because the ease of use will ensure that many users will likely use the app in the future. The respondents' feedback on ease of use is summarized in Figure 7. 


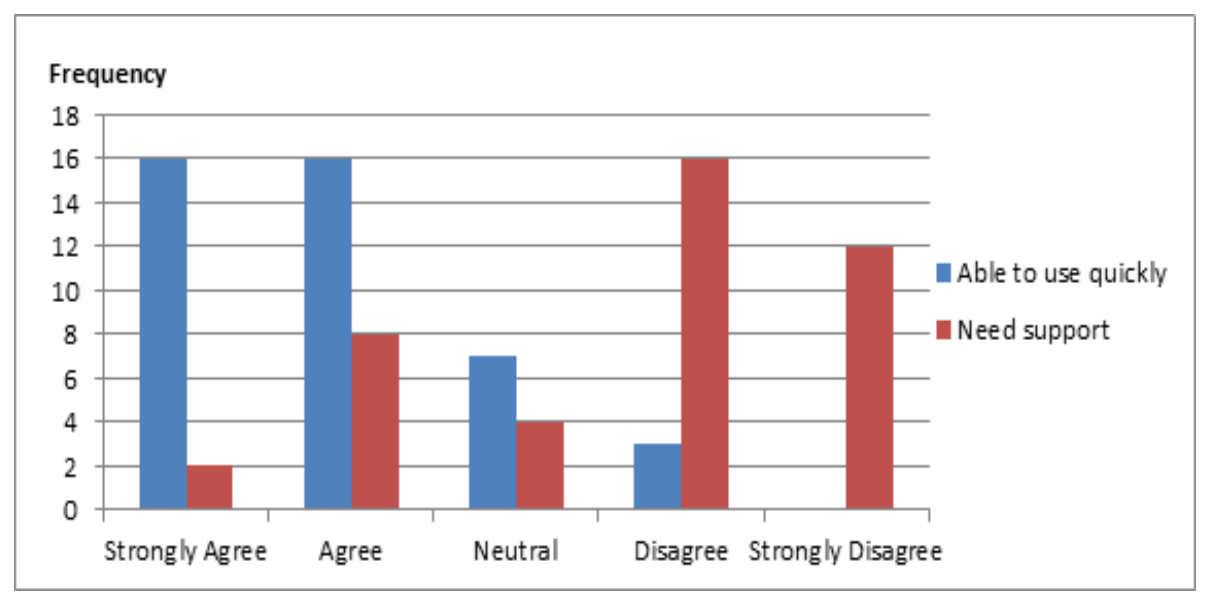

Fig. 7. "Ease of Use of M@LC App"

The feedback from respondents shows that most of the respondents are able to use the app quickly and less than three respondents need support in using M@LC app. The respondents were then asked whether they are confident to use M@LC app in the future. Their responses are gathered in Figure 8.

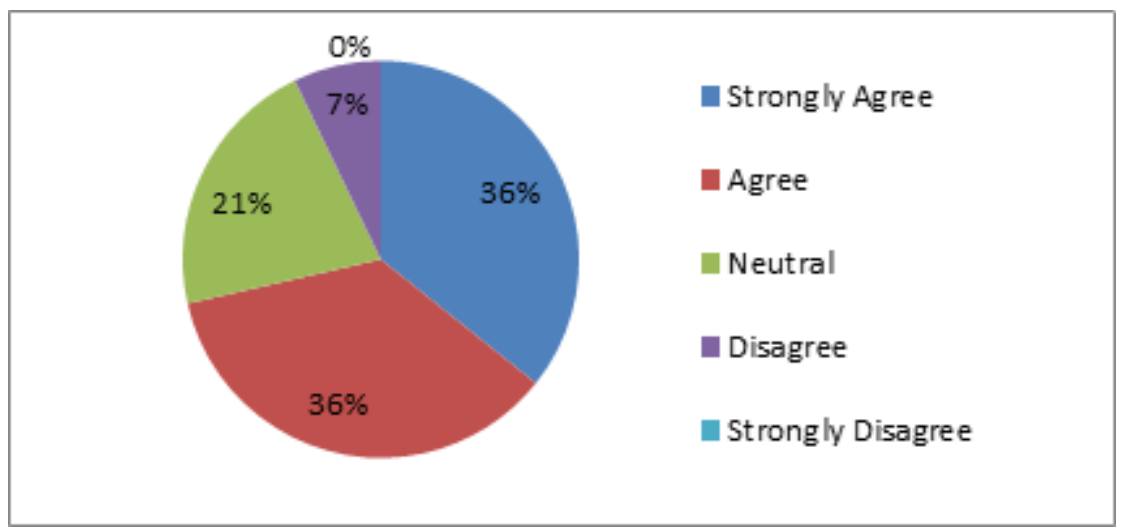

Fig. 8. Responses on item "Confident to use M@LC App"

72\% of the respondents are confident to use M@LC app. On the other hand, 7\% are not confident enough to use the app. $21 \%$ is neutral probably with some more enhancements in the app, these respondents can have confidence in using M@LC app. After that, the respondents are asked if they would like to use the app frequently after M@LC app is available in the market soon. Their feedback is as depicted in Figure 9. 


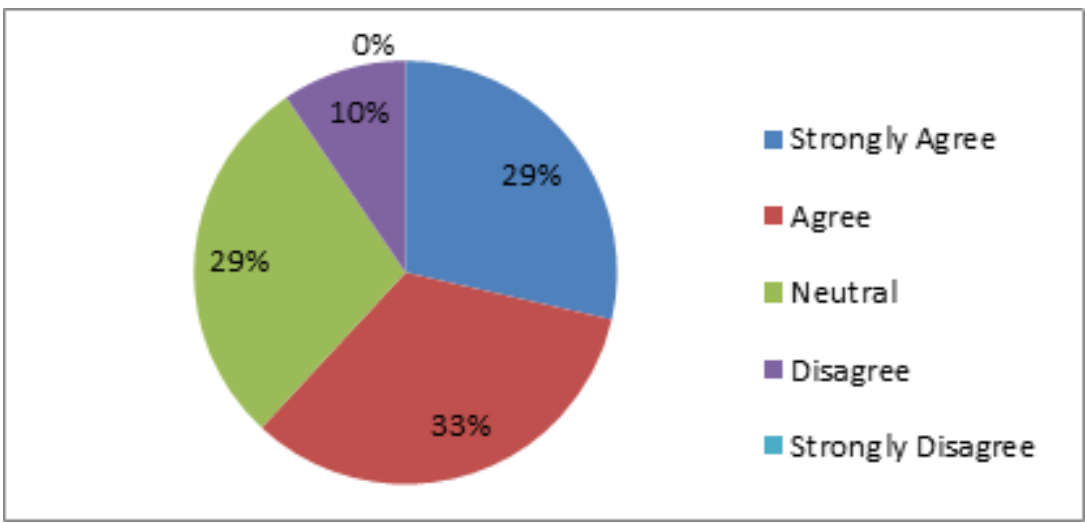

Fig. 9. Responses on item "Willing to use M@LC Frequently"

Percentage of respondents who are willing to use M@LC app in the future is $62 \%$. However, there are $10 \%$ of the respondents who are not willing to use the app in the future. Enhancement or improvement in the app must be taken into account to ensure that these respondents and new respondents will use the app in the future.

There are many positive comments from respondents about the app. However there are a few suggestions that should be considered in improving the app before being released to the market.

\section{Conclusion}

This study examines the potential and benefits of local knowledge in providing the best recommendation solution for a certain problem. In specific, this study helps users to find the best eatery venue based on local recommendation using mobile phone. By integrating local knowledge, the M@LC business is proposed. It defines the M@LC app's business concept which is a rural innovation ecosystem involving multiple entities (locals, eatery owners and users who are searching for eatery). The innovation highlights on local knowledge crowdsourced from local participation using the M@LC app. As for the revenue stream, the innovation generates revenue from the subscription fees from participated eatery owner and also ad sales. In addition, the Makan @Local Chatok app was developed to simulate the proposed business model. The type of users for the app consists of admin, reviewer, user, and eatery owner. It was found that the prototype was successfully built and tested.

Although considerable future works remain, this study has demonstrated that Makan@Local Chatok Business Model is significant as a guideline for local to leverage business in eatery business perspective. From the findings obtained in this study, there were indications that open up new means for mobile app developer to capture local knowledge into their system for other business field. In conclusion, it is hoped that this study will not only demonstrate the potential and impact of mobile eatery recommendation system using local knowledge, but also provide a capstone on business research in the field of tourism industry. 


\section{Acknowledgement}

We would like to acknowledge the valuable contributions to Universiti Utara Malaysia for awarding us with the Research Generation University Grant (Living Lab Research of ICC UUM), with SO Code: 13555 to carry out this research project, and the Innovation and Commercialization Centre (ICC) UUM for their support while carrying out this study.

\section{$7 \quad$ References}

[1] Afshari, A., Mojahed, M., \& Yusuff, R. M. (2010). Simple additive weighting approach to personnel selection problem. International Journal of Innovation, Management and Technology, 1(5), 511-515. Retrieved from. http://www.ijimt.org/papers/89-M474.pdf.

[2] Bao, J., Zheng, Y., \& Mokbel, M. F. (2012). Location-based and preference-aware recommendation using sparse geo-social networking data. In Proceedings of the 20th international conference on advances in geographic information systems, 199-208. https:// doi.org/10.1145/2424321.2424348

[3] Bergvall-Kareborn, B. H. M. S. A., Hoist, M., \& Stahlbrost, A. (2009, January). Concept design with a living lab approach. In 2009 42nd Hawaii International Conference on System Sciences (pp. 1-10). IEEE. https://doi.org/10.1109/hicss.2009.123

[4] Bozhi, Y., Bin, X., Tonglee, C., Kaiyan, S., \& Yongbin, L. (2014). Mobile Phone Recommendation Based on Phone Interest. In Web Information Systems Engineering WISE 2014 (p. 308-323). Springer International Publishing, Switzerland. https://doi.org/ $10.1007 / 978-3-319-11749-2 \quad 24$

[5] Budiman, R. (2013). Utilizing Skype for providing learning support for Indonesian distance learning students: A lesson learnt. Procedia - Social and Behavioral Sciences, 83: 5-10 https://doi.org/10.1016/j.sbspro.2013.06.002

[6] Cecile, M. \& Christele, C. (2013). Toward an identification of elements contributing to satisfaction with the tourism experience. Journal of Vacation Marketing, 19(1), 19-39. https://doi.org/10.1177/1356766712468733

[7] Chandrasena Premawardhena, N., ICT in the foreign language classroom in Sri Lanka: A journey through a decade. 10th World Conference on Computers in Education (WCCE 2013), Nicolaus Copernicus University, July 2-5 2013, Torun, Poland.pp 223-224

[8] Dickin, S.K., Schuster-Wallace, C.J., \& Elliott, S.J. (2013). Mosquitoes \& vulnerable spaces: Mapping local knowledge of sites for dengue control in Seremban and Putrajaya Malaysia. Applied Geography, Vol 46(), pp 71-79. https://doi.org/10.1016/j.apgeog.2013. 11.003

[9] Edwards- Schachter, M. E., Matti, C. E., \& Alcántara, E. (2012). Fostering quality of life through social innovation: A living lab methodology study case. Review of Policy Research, 29(6), 672-692. https://doi.org/10.1111/j.1541-1338.2012.00588.x

[10] Espeter, M. \& Raubal, M. (2009). Location-based decision support for user groups. Journal of Location Based Services, Vol. 3, Iss. 3. https://doi.org/10.1080/17489720903339668

[11] H. Nakahara, T. Yanagisawa and K. Yamamoto, "Study on a Web-GIS to Support the Communication of Regional Knowledge in Regional Communities: Focusing on Regional Residents' Experiential Knowledge”, Socio- Informatics, Vol.1, No.2, pp.77-92, 2012. 
[12] Jadhav, A. S., \& Sonar, R. M. (2008) A hybrid system for selection of the software packages. International Conference on Emerging Trends in Engineering and Technology, 337-342. doi: https://doi.org/10.1109/icetet.2008.7

[13] Kim, S., \& Chung, J. (2011). Restaurant Selection Criteria: Understanding the Roles of Restaurant Type and Customers' Sociodemographic Characteristics.

[14] Kontos, T. D., Komilis, D. P., \& Halvadakis, C. P. (2005). Siting MSW landfills with a spatial multiple criteria analysis methodology. Waste management, 25(8), 818-832. doi: https://doi.org/10.1016/j.wasman.2005.04.002

[15] Lathia, Neal. (2015). The anatomy of mobile location-based recommender systems.Recommender Systems Handbook. Springer, 493-510. https://doi.org/10.1007/ 978-1-4899-7637-6 14

[16] Law, F. L., Kasirun, Z. M., \& Gan, C. K. (2011, December). Gamification towards sustainable mobile application. In 2011 Malaysian Conference in Software Engineering (pp. 349-353). IEEE. https://doi.org/10.1109/mysec.2011.6140696

[17] Mellado, T., Brochier, T., Timor, J., \& Vitancurt, J. (2014). Use of local knowledge in marine protected area management. Marine Policy, 44, 390-396. https://doi.org/10.1016/ j.marpol.2013.10.004

[18] Nakahara, H., Yanagisawa, T., \& Yamamoto, K. (2012). Study on a web-GIS to support the communication of regional knowledge in regional communities: focusing on regional residents' experiential knowledge. Socio-Informatics, 1(2), 77-92.

[19] Nielsen, J. (1994). Usability Engineering, Academic Press Inc.

[20] Nugraha, F. (2013). Decision support system for evaluation procurement of goods with Simple Additive Weighting Method (SAW). International Conference on Information Systems for Business Competitiveness, 211-215. Retrieved from http://eprints.undip.ac. id/41795/1/38-_Fajar_Nugraha.pdf

[21] Oliver, D.M., Fish, R.D., Winter, M., Hodgson, C.J., Heathwaite, A.L., \& Chadwick, D.R. (2012). Valuing local knowledge as a source of expert data: Farmer engagement and the design of decision support systems. Environmental Modelling \& Software, Vol 36(2012), pp 76-85. https://doi.org/10.1016/j.envsoft.2011.09.013

[22] Omar, M. F. B., Trigunarsyah, B., \& Wong, J. (2018). Two-Envelope System for Consultant Selection using Weighted Sum Model. International Journal of Engineering \& Technology, 7(4.27), 121-125. https://doi.org/10.14419/ijet.v7i4.27.22498

[23] Ortega, F., Bobadilla, J., Hernando, A., \& Gutiérrez, A. (2013). Incorporating group recommendations to recommender systems: Alternatives and performance. Information Processing \& Management, 49(4), 895-901. https://doi.org/10.1016/j.ipm.2013.02.003

[24] Padmanaba, M., Sheil, D., Basuki, I., \& Liswanti, N. (2013). Accessing Local Knowledge to Identify Where Species of Conservation Concern Occur in a Tropical Forest Landscape. Environmental Management, Vol 52(2), pp 348-359. https://doi.org/10.1007/s00267-013$\underline{0051-7}$

[25] Pallot, M., Trousse, B., Senach, B., \& Scapin, D. (2010, August). Living lab research landscape: From user centred design and user experience towards user cocreation. In First European Summer School" Living Labs".

[26] Pavan \& Todeschini (2009). Multicriteria Decision Making Methods. In SD Brown, R. Tauler, \& B. Walczak (a cura di), Comprehensive Chemometrics (pp. 591-629). Elsevier. https://doi.org/10.1016/b978-044452701-1.00038-7

[27] Peters-Guarin, G., McCall, M. K., \& van Westen, C. (2012), Coping strategies and risk manageability: using participatory geographical information systems to represent local knowledge. Disasters, 36: 1-27. https://doi.org/10.1111/j.1467-7717.2011.01247.x 
[28] Putra, A. J., Abdillah, L. A., \& Yudiastuti, H. (2016). Penentuan sekolah dasar negeri terbaik kota Palembang dengan metode weighted sum model (WSM) dan weighted product model (WPM) menggunakan visual basic. net 2015. https://doi.org/10.30645/ jurasik.v3i0.70

[29] Rinner, C. \& Raubal, M. (2004). Personalized multi-criteria decision strategies in locationbased decision support. Journal of Geographic Information Sciences, 10, 149-156.

[30] Sahir, S. H., Rosmawati, R., \& Minan, K. (2017). Simple Additive Weighting Method to Determining Employee Salary Increase Rate. Int. J. Sci. Res. Sci. Technol, 3(8), 42-48.

[31] Simon, H. (1996). The Sciences of Artificial (3rd ed.). MIT Press, Cambridge, MA, USA.

[32] Sousa, J., Vicente, L., Gippoliti, S., Casanova, C. and Sousa, C. (2014), Local knowledge and perceptions of chimpanzees in Cantanhez National Park, Guinea-Bissau. Am. J. Primatol., 76: 122-134. https://doi.org/10.1002/ajp.22215

[33] T. Yanagisawa and K. Yamamoto, "Study on Information Sharing GIS to Accumulate Local Knowledge in Local Communities", Theory and Applications of GIS, Vol.20, No.1, pp.6170, 2012. https://doi.org/10.5638/thagis. 20.61

[34] Triantaphylluo, E. (2000). Multi-Criteria Decision Making methods: a comparative study. Netherlands: Kluwer Academic Publishers.

[35] Vaishnavi, V. K. \& Kuechler, W. J. (2007). Design Science Research Methods and Patterns: Innovating Information and Communication Technology (1st ed.). Auerbach Publications, Boston, MA, USA. https://doi.org/10.1201/b18448

[36] White, R., \& Buscher, G. (2012). Characterizing local interests and local knowledge. SIGCHI Conference on Human Factors in Computing Systems, 1607-1610. https://doi. org/10.1145/2207676.2208283

[37] Y. Ge, H. Xiong, A. Tuzhilin, K. Xiao, M. Gruteser, \& M. Pazzani (2010). An energyefficient mobile recommender system. In Proceedings of the 16th ACM SIGKDD International Conference on Knowledge Discovery and Data Mining, ACM, Washington, DC, USA, pp. 899-908. https://doi.org/10.1145/1835804.1835918

[38] Yanagisawa, T., \& Yamamoto, K. (2012). Study on information sharing GIS to accumulate local knowledge in local communities. Theory and Applications of GIS, 20(1), 61-70. https://doi.org/10.5638/thagis.20.61

[39] Yin, H., Sun, Y., Cui, B., Hu, Z., \& Chen, L. (2013). Lcars: a location-content-aware recommender system. In Proceedings of the 19th ACM SIGKDD international conference on Knowledge discovery and data mining (pp. 221-229). ACM. https://doi.org/10.1145/ $\underline{2487575.2487608}$

\section{Authors}

Siti Mahfuzah Sarif is a senior lecturer in the Department of Multimedia Technology at School of Multimedia Technology \& Communication, UUM. Her work focuses specifically on the recommendation system design incorporating MCDM techniques and Multimedia design principles. She has collaborated actively with researchers in several other disciplines of ICT and Multimedia, particularly in Multimedia Learning, Interactive Advertising, and Virtual Reality. Email: ctmahfuzah@uum.edu.my

Zurina Hanafi is a Senior Lecturer at the School of Quantitative Sciences, Universiti Utara Malaysia. Her research interest covers green logistics, sustainable food supply chain, multimodal transportation planning and carbon emission related issues. 
She is interested in integrating optimisation methods in logistics strategic planning with consideration of environmental impact. Email: h.zurina@uum.edu.my

Shafinah Farvin Packeer Mohamed holds a diploma from UNISHAMS in the year 2003 and a Bachelor Degree from Universiti Utara Malaysia in the year 2008. Her Ph.D. was obtained from the same university in the year 2015. Her research interest is related to software process quality, software process assessment and certification, Agile software process and multicriteria decision making. She is currently a lecturer in the School of Computing, Universiti Utara Malaysia and the coordinator for UUM-ABS program. Email: shafinah@uum.edu.my

Syamsul Bahrin Zaibon is an Associate Professor at the School of Creative Industry Management \& Performing Arts (SCIMPA) in Universiti Utara Malaysia (UUM). As a game based learning expert, he has published massive articles on mobile learning and mobile game development in prestigious academic journals and conferences. His previous inventions have accomplished gold, bronze and silver medals in PECIPTA2019, PECIPTA 2009, SIIF2009 and ITEX2014. Email: syamsulbahrin@uum.edu.my

Mohamad Farhan Mohamad Mohsin is currently the Deputy Dean of UUM CAS Student Development \& Alumni Office and a senior lecturer at the School of Computing, UUM College of Arts \& Sciences, UUM. He has a deep desire to discover the secret of machine learning principle, algorithm, intelligent system, and its capability to infer human cognition and decision-making process. At the moment, most of his research are in anomaly detection and data analytic related modeling mainly in climate change studies and outbreak. Now he is engaging with artificial immune system, several bio-inspired approaches, and text mining based research. Email: farhan@uum.edu.my

Article submitted 2020-01-22. Resubmitted 2020-03-13. Final acceptance 2020-03-13. Final version published as submitted by the authors. 